\title{
Two Massive Hydraulic Tests Completed in Deep KTB Pilot Hole
}

\author{
by Hans-Joachim Kümpel, Jörg Erzinger, and Serge A. Shapiro
}

doi:10.2204/iodp.sd.3.05.2006

\section{Introduction}

The German Continental Deep Drilling Program (KTB) boreholes in Windischeschenbach, Bavaria, Germany have revealed a wealth of geoscientific data during the years of pre-drilling surveys (1984-1986), the drilling phase (19871994), and the subsequent deep-crustal laboratory phase (1995-2000, e.g. Emmermann \& Lauterjung, 1997). In 2001, a new series of experiments were launched within and around the two KTB boreholes, the 4.0-km-deep pilot hole (KTBVB), and the 9.1-km-deep main hole (KTB-HB; Fig. 1). These experiments address the spatial extension of fluid flow and fluid systems in the Earth's crystalline crust, their impact on physical rock parameters, rheology, the dynamics and mechanical stability of the crust, and the transport of soluble matter. Studies of these parameters under in situ conditions are of fundamental geoscientific and societal interest in areas such as the optimal use of fluid and thermal reservoirs, the safe disposal of critical wastes, and understanding seismogenesis, particularly in connection with large lake reservoirs.

The use of the KTB site as a crustal laboratory addressing the role of rock fluids is supported by a wealth of exceptional surface and borehole data, two accessible boreholes in crystalline rock, at only $200 \mathrm{~m}$ apart, and the occurrence of two distinct, extended fault systems, named seismic reflectors SE1 and SE2, at roughly 7 and $4 \mathrm{~km}$ depths, respectively.

The new series of KTB experiments are part of a research program entitled "Energy and Fluid Transport in Continental Fault Systems". The first phase of experiments involved

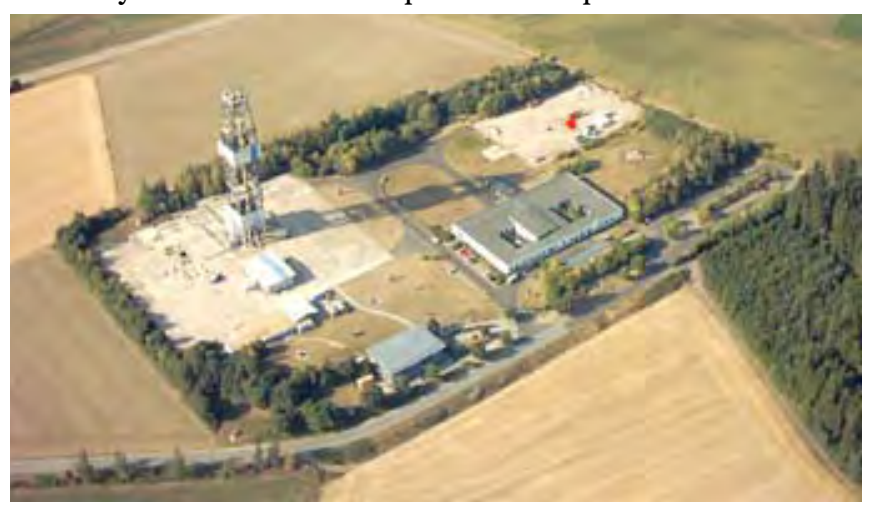

Aerial view of KTB site with former drill tower atop main hole KTB-HB and pilot hole KTB-VB in center of second light, rectangular area (red circle)
Table 1: Rough schedule of production and injection tests at KTBVB (neglecting rate changes lasting 100 hours or less); negative rate: injection.

\begin{tabular}{|c|c|}
\hline Duration & Rate $\left(\mathrm{L} \cdot \mathrm{min}^{-1}\right)$ \\
\hline 21 Jun $2002-2$ Oct 2002 & 29 \\
\hline 11 Oct 2002 - 23 Oct 2002 & 29 \\
\hline 3 Oct 2002 - 20 Dec 2002 & 57 \\
\hline 7 Jan 2003 - 27 Jun 2003 & 58 \\
\hline 17 Jun 2004 - 17 Jul 2004 & -196 \\
\hline 9 Aug 2004 - 24 Aug 2004 & -186 \\
\hline 2 Sep 2004 - 30 Apr 2005 & -185 \\
\hline
\end{tabular}

massive hydraulic tests in KTB-VB to probe the SE2 fault system at a depth of $4 \mathrm{~km}$ and included a production test and an injection test, with subsequent recovery periods. A second phase of hydraulic tests is currently under planning and is intended to probe the more seismically reflective fault system $\mathrm{SE} 1$ at a depth of $\sim 7.2 \mathrm{~km}$.

\section{One-Year Production Test}

A production test within Phase I was conducted from June 2002 to June 2003. A submersible pump was lowered to a depth of $1284 \mathrm{~m}$ within hole KTB-VB, and $22,300 \mathrm{~m}^{3}$ of $119^{\circ} \mathrm{C}$ in situ saline fluids were produced from clefts in contact with the open-hole section, at 3850-4000 m depth. An initial production rate of $29 \mathrm{~L} \cdot \mathrm{min}^{-1}$ (Table 1) resulted in a fluid-level draw down of only $280 \mathrm{~m}$ after the first four months, or less than one-third of the expected value. The production rate was therefore doubled for the rest of the test, and the fluid level reached a maximum draw down of $605 \mathrm{~m}$ in June 2003. Various geophysical, hydraulic, and geochemical parameters were monitored online at the site and were analyzed mostly in real time. Crustal fluids and gases were sampled regularly for detailed geochemical, geobiological, and isotopic investigations. The totalvolume of produced fluids was about fifty times larger than obtained by the largest previous

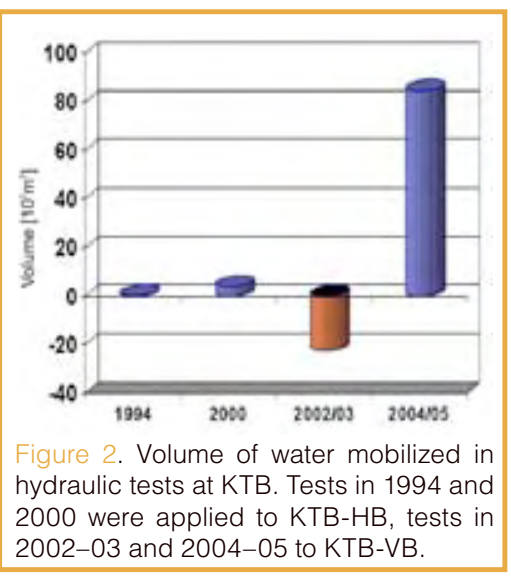


pump test in KTB-VB in 1991, and it was less affected by residuals of drilling mud (Erzinger \& Stober, 2005).

Specific results of the production test can be summarized as follows. The gas-to-water volume ratio was found to be 0.95-1.05 at surface conditions. Salinity of the formation water is about twice as high as seawater (Möller et al., 2005). Concentrations of most dissolved matter, including gases, were constant throughout the test period. When the fluid production rate was raised, only $\mathrm{Ra}$ and $\mathrm{Rn}$ concentrations increased because of different scavenging rates from pore and fracture surfaces (Lippmann et al., 2005). Ra and Rn appear to be in radiochemical equilibrium.

Investigations into the chemical and isotopic composition of fluids and gases have given hints to the origin and genesis of crustal gases and fluids. The probable source region is Mesozoic seawater or formation water from PermoCarboniferous sedimentary rocks of the Weiden embayment, beginning some $10 \mathrm{~km}$ southwest of the site (Fehn \& Snyder, 2005; Möller et al., 2005). Organic matter suggestive of deep microbial activity was not unambiguously identified.

The hydraulic conductivity of the rocks surrounding the KTB-VB open-hole section is surprisingly high. The bulk hydraulic permeability of the SE2 fault system was found to be $2 \times 10^{-15} \mathrm{~m}^{2}$ (hydraulic conductivity $=10^{-8} \mathrm{~m} \mathrm{~s}^{-1}$ ), about one order of magnitude higher than rocks outside SE2 (Stober \& Bucher, 2005; Gräsle et al., 2006; McDermott et al., 2006). The fault system clearly dominates fluid flow on the regional scale. In KTB-HB the fluid level was lowered by about $50 \mathrm{~m}$ in response to the fluid withdrawal at KTB-VB. Induced seismicity was not observed during the pump test.

\section{Ten-Month Injection Test}

A fluid injection test was conducted from June 2004 until April 2005 following a one-year recovery phase from the production test (Table 1). An electrically powered threepiston pump was operated at the surface to deliver a total of $84,600 \mathrm{~m}^{3}$ of fresh water into the open-hole section of KTBVB during the course of the test. Well-head pressure gradually dropped from roughly 120 bar to about 90 bar within the first two months, then slowly increased to $115 \mathrm{bar}$ in April 2005. The total volume injected was twenty-one times larger than during a three-month injection test in August-October 2000 in KTB-HB and 4000 times larger than a short-term injection test at the end of the drilling phase in December 1994 (Zoback \& Harjes, 1997; Baisch et al., 2002; Fig. 2).

Again, various geophysical and hydraulic parameters were monitored during the test, and particular attention was given to possible induced seismicity and its relation to pore pressure. Specific results of the injection test and of some of the companion experiments can be summarized as follows. About 3000 micro-seismic events were detected by the

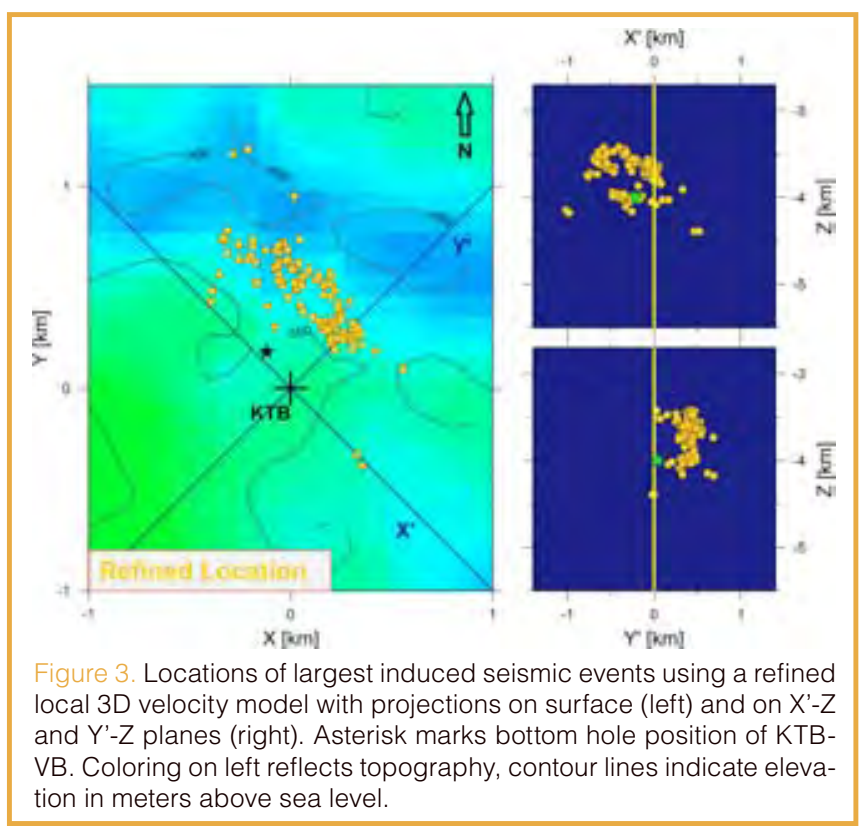

borehole geophone in the low-noise environment in KTB$\mathrm{HB}$, and 150 events were seen by the local seismic network at the surface (Fig. 3). Analysis of those data has revealed that seismicity induced by injecting fluid directly into a crustal fault remains guided by this fault and is triggered by porepressure perturbations as low as 0.01-1.00 bar at hypocenters (Shapiro et al., 2006). Most notable was the observation that seismicity started only after injecting a fluid volume approximately equivalent to the amount previously extracted by the pump test into the incompletely saturated formations. The crystalline crust at KTB site was mechanically stable when pore pressure was reduced from its natural level by the pump test, but became transiently destabilized when the reinjection of fluids created a positive pore-pressure perturbation. Pore pressure diffusion ,therefore, appears to act as the dominant mechanism for triggering seismicity.

Given the rather large amount of water that was injected, seismicity generated by this test was much weaker than seismicity induced by the injection tests in 1994 and 2000 in KTB-HB. Obviously, the pressure build-up in 2004-2005 also was much weaker, because the hydraulic transmissivity of the SE2 fault system is much higher than that of the rock formations that took up the injected water during the previous tests.

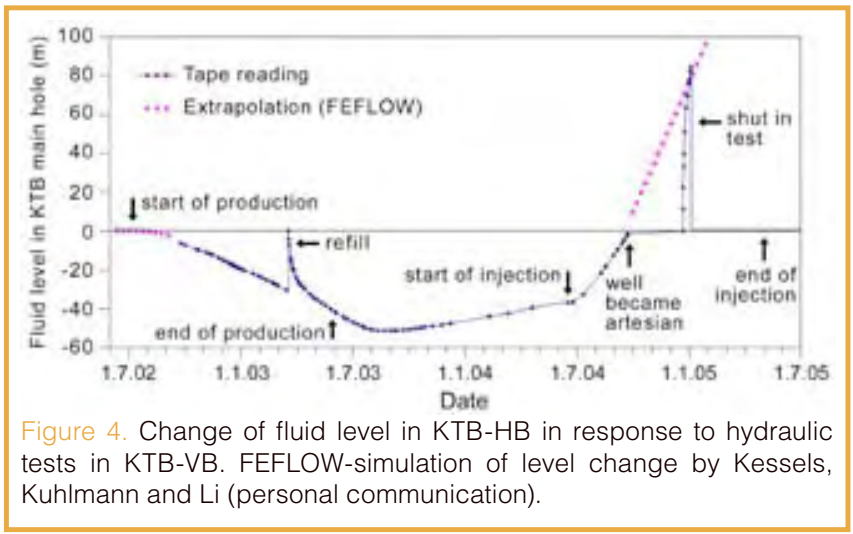


The fluid level in KTB-HB rose sharply several days after the injection started in KTB-VB (Gräsle et al., 2006). KTB-HB became artesian in October 2005 (Fig. 4), with an outflow of about $1 \mathrm{~m}^{3} \cdot \mathrm{day}^{-1}$ at the end of the injection test. Since then, both boreholes were kept mostly shut. One year after the injection ceased, the boreholes are still under excess fluid pressure. Hydraulic communication from KTB-VB into KTB-HB actually occurred through a previously identified leakage in the casing of KTB-HB at 5200-5600 m depth (Baisch et al., 2002).

\section{Ongoing and Future Research}

We continue to monitor the fluid pressure decay in both boreholes to assess the capability of the faults to recover from the fluid injection. Full recovery of the fluid pressure is not expected before 2008. Other ongoing experiments include push-pull tracer tests in KTB-VB, monitoring of the surface deformation field through borehole tiltmeters of nano-radian resolution (Jahr et al., 2006), and repeated reflection seismics and DC resistivity measurements to map induced changes in reflectivity and electrical conductivity of the SE2 fault system, respectively.

The successful completion of the Phase I hydraulic tests in KTB-VB can answer many of the questions we had in 2001. The plan to conduct hydraulic tests in the SE1 fault system at $7.2 \mathrm{~km}$ depth by perforating KTB-HB presents an experimental challenge yet to be overcome in Phase II of this program. Since the seismic signature of SE1 is much more pronounced than that of SE2, new findings are likely on transport properties and the mechanical stability of the crust; however, this would require stopping the leaks in the casing and clearing away equipment lost in the hole.

\section{Acknowledgements}

We are thankful for substantial financial support from the Deutsche Forschungsgemeinschaft and GeoForschungsZentrum Potsdam. The hydraulic tests were enabled by help from the Operational Support Group of the International Continental Scientific Drilling Program (ICDP) and by invaluable on-site support from Miel Kühr and Karl Bohn. About twenty scientists and ten students were involved in the various investigations.

\section{References}

Baisch, S., Bohnhoff, M., Ceranna, L., Yimin Tu, and Harjes, H.-P., 2002. Probing the crust to $9 \mathrm{~km}$ depth: fluid-injection experiments and induced seismicity at the KTB superdeep drilling hole, Germany. Bull. Seismol. Soc. Am., 92:2369-2380, doi:10.1785/0120010236.

Emmermann, R., and Lauterjung, J., 1997. The German Continental Deep Drilling Program KTB: Overview and major results. J. Geophys. Res., 102:18179-18201, doi:10.1029/96JB03945.

Erzinger, J., and Stober, I., 2005. Introduction to special issue: longterm fluid production in the KTB pilot hole, Germany. Geofluids, 5:1-7, doi:10.1111/j.1468-8123.2004.00107.x.

Fehn, U., and Snyder, G.T., 2005. Residence times and source ages of deep crustal fluids: interpretation of ${ }^{129} \mathrm{I}$ and ${ }^{36} \mathrm{Cl}$ results from the KTB-VB drill site, Germany. Geofluids, 5:42-51, doi:10.1111/j.1468-8123.2004.00105.x.

Gräsle, W., Kessels, W., Kümpel, H.-J., and Li, X., 2006. Hydraulic observations from a one year fluid production test in the $4000 \mathrm{~m}$ deep KTB pilot borehole. Geofluids, 6:8-23.

Jahr, T., Letz, H., and Jentzsch, G., 2006. Monitoring fluid induced deformation of the earth's crust: A large scale experiment at the KTB location/Germany. J. Geodyn., 41(1-3):190-197, doi:10.1016/j.jog.2005.08.003.

Lippmann, J., Erzinger, J., Zimmer, M., Schloemer, S., Eichinger, L., and Faber, E., 2005. On the geochemistry of gases and noble gas isotopes (including ${ }^{22} \mathrm{Rn}$ ) in deep crustal fluids: the $4000 \mathrm{~m}$ KTB-pilot hole fluid production test 2002-03. Geofluids, 5:52-66, doi:10.1111/j.1468-8123.2004.00108.x.

McDermott, C.I., Lodemann, M., Ghergut, I., Tenzer, H., Sauter, M., and Kolditz, O., 2006. Investigation of coupled hydraulicgeomechanical processes at the KTB site: pressuredependent characteristics of a long-term pump test and elastic interpretation using a geomechanical facies model. Geofluids, 6:67-81, doi:10.1111/j.1468-8123.2006.00129.x.

Möller, P., Woith, H., Dulski, P., Lüders, V., Erzinger, J., Kämpf, H., Pekdeger, A., Hansen, B., Lodemann, M., and Banks, D., 2005. Main and trace elements in KTB-VB fluid: composition and hints to its origin. Geofluids, 5:28-41, doi:10.1111/ j.1468-8123.2004.00104.x.

Shapiro, S.A., Kummerow, J., Dinske, C., Asch, G., Rothert, E., Erzinger, J., Kümpel, H.-J., and Kind, R., 2006. Fluid induced seismicity guided by a continental fault - Injection experiment of 2004/2005 at the German deep drilling site (KTB). Geophys. Res. Lett., 33:L01309, doi: 10.1029/2005GL024659.

Stober, I., and Bucher, K., 2005. The upper continental crust, an aquifer and its fluid: hydraulic and chemical data from $4 \mathrm{~km}$ depth in fractured crystalline basement rocks at the KTB test site. Geofluids, 5:8-19, doi:10.1111/j.14688123.2004.00106.x.

Zoback, M.D., and Harjes, H.-P., 1997. Injection-induced earthquakes and crustal stress at $9 \mathrm{~km}$ depth at the KTB deep drill site, Germany. J. Geophys. Res., 102:18477-18491, doi:10.1029/96JB02814.

\section{Authors}

Hans-Joachim Kümpel, Leibniz Institute for Applied Geosciences (GGA), Stilleweg 2, D-30655 Hannover, Germany, e-mail: kuempel@gga-hannover.de

Jörg Erzinger, GeoForschungsZentrum Potsdam, Telegraphenberg, D-14473 Potsdam, Germany.

Serge A. Shapiro, Institute for Geological Sciences, Free University Berlin, Malteserstr. 74-100, D-12249 Berlin, Germany.

\section{Related Web Link}

http://ktb.icdp-online.org/

\section{Figure Credits}

Fig. 1: photograph by Miel Kühr

Fig. 3: photograph by Günter Asch and Jörn Kummerow 